\title{
The alcohol-preferring (P) and high-alcohol-drinking (HAD) rats - Animal Models of Alcoholism
}

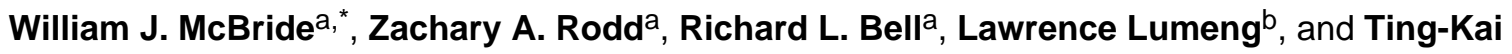 \\ $\mathbf{L i}^{\mathrm{C}}$ \\ anstitute of Psychiatric Research, Department of Psychiatry, Indiana University School of \\ Medicine, Indianapolis, IN 46202 \\ ${ }^{b}$ Department of Medicine, Indiana University School of Medicine, Indianapolis, IN 46202 \\ 'Department of Medicine, Duke University School of Medicine, Durham, NC 27710
}

\section{Abstract}

The objective of this article is to review the literature on the utility of using the selectively bred alcohol-preferring $(\mathrm{P})$ and high-alcohol-drinking (HAD) lines of rats in studies examining high alcohol drinking in adults and adolescents, craving-like behavior, and the co-abuse of alcohol with other drugs. The $\mathrm{P}$ line of rats meets all of the originally proposed criteria for a suitable animal model of alcoholism. In addition, the P rat exhibits high alcohol-seeking behavior, demonstrates an alcohol deprivation effect (ADE) under relapse drinking conditions, consumes amounts of ethanol during adolescence equivalent to those consumed in adulthood, and co-abuses ethanol and nicotine. The $\mathrm{P}$ line also exhibits excessive binge-like alcohol drinking, attaining blood alcohol concentrations (BACs) of $200 \mathrm{mg} \%$ on a daily basis. The HAD replicate lines of rats have not been as extensively studied as the P rats. The HAD1,2 rats satisfy several of the criteria for an animal model of alcoholism, e.g., these rats will voluntarily consume ethanol in a free-choice situation to produce BACs between 50-200 mg\%. The HAD1,2 rats also exhibit an ADE under repeated relapse conditions, and will demonstrate similar levels of ethanol intake during adolescence as seen in adults. Overall, the $\mathrm{P}$ and HAD1,2 rats have characteristics attributed to an early onset alcoholic, and can be used to study various aspects of alcohol use disorders.

\section{Keywords}

alcohol-preferring $(\mathrm{P})$ rat; high-alcohol-drinking (HAD) rat; animal model of alcoholism; binge drinking; alcohol-seeking behavior

\footnotetext{
(C) 2013 Elsevier Inc. All rights reserved.

"Corresponding author: Dr. W.J. McBride, Indiana, University School of Medicine, Institute of Psychiatric Research, 791 Union Dr., Indianapolis, IN 46202-4887, Tel: +1 317274 3820, Fax: +1 317274 1365, wmcbride @iupui.edu.

None of the authors has a conflict of interest associated with this research. The content of this manuscript is solely the responsibility of the authors and does not necessarily represent the official views of the NIAAA or NIH.

Publisher's Disclaimer: This is a PDF file of an unedited manuscript that has been accepted for publication. As a service to our customers we are providing this early version of the manuscript. The manuscript will undergo copyediting, typesetting, and review of the resulting proof before it is published in its final citable form. Please note that during the production process errors may be discovered which could affect the content, and all legal disclaimers that apply to the journal pertain.
} 


\section{Introduction}

Animal models are very valuable tools for examining normal and abnormal functions of the brain and behavior. Animal models are useful when they reveal some aspect of a complex human condition. The development of an animal model of alcoholism has been difficult because common stock animals do not usually voluntarily consume alcohol under freechoice conditions without experimental manipulations. However, rodents exhibit a wide range of alcohol-drinking preferences (Richter \& Campbell, 1940), and this behavior can be genetically influenced (McClearn \& Rodgers, 1959). Through selective breeding, several high and low alcohol-consuming rat lines have been developed (Eriksson, 1969; Fadda, Mosca, Colombo, \& Gessa, 1989; Mardones \& Segovia-Riquelme, 1983), including the alcohol-preferring (P) and high-alcohol-drinking (HAD) lines of rats (Li, Lumeng, \& Doolittle, 1993; Li, Lumeng, Doolittle, \& Carr, 1991; Li, Lumeng, McBride, \& Waller, 1981; Lumeng, Hawkins, \& Li, 1977). These lines were developed from different foundation stocks; they exhibit certain similar phenotypes (e.g., high ethanol intakes) and some behavioral and neurobiological differences (reviewed in McBride \& Li, 1998; Murphy et al., 2002).

The $\mathrm{P}$ and HAD lines of rats have been selected on the basis of their daily free-choice intake of a $10 \%$ ethanol solution vs. water, with food always available, and on their preference for the alcohol solution over water. The use of both criteria helps to eliminate rats with high fluid intake. The $\mathrm{P}$ and HAD lines were selected on the basis of minimum daily ethanol intakes of $5 \mathrm{~g} / \mathrm{kg}$, and a preference ratio of 2:1 of $10 \%$ ethanol: water in volume of intake. Ideally, it would be important to also include a 3rd criterion of ethanol intakes producing pharmacologically meaningful blood alcohol concentrations (BACs), i.e., $50 \mathrm{mg} \%$ and higher.

BACs are related to the amount and pattern of ethanol intake. Under the 24-h free-choice conditions (10\% ethanol vs. water) used for selection, the P rat consumed approximately $70 \%$ of its total ethanol intake during the dark cycle (Murphy et al., 1986). The P rats appeared to drink in discrete bouts (average intake of $1.3 \pm 0.1 \mathrm{~g} / \mathrm{kg} /$ episode during dark phase); retro-orbital samples taken at set times in the dark phase $(1,3,6$, and $12 \mathrm{~h}$ after lights were turned off) indicated BACs had an average range from 40 to $90 \mathrm{mg} \%$ (Murphy et al., 1986). With 4-h scheduled access (10\% ethanol vs. water) starting at onset of the dark phase, $\mathrm{P}$ rats consumed $2.1 \pm 0.2 \mathrm{~g} / \mathrm{kg} / 4 \mathrm{~h}$, with ethanol intakes occurring almost exclusively within the first $15 \mathrm{~min}$; BACs peaked at approximately $120 \mathrm{mg} \%$ (Murphy et al., 1986). When $\mathrm{P}$ rats were given access to $10 \%$ ethanol vs. water for four 1 -h ethanol access periods across the 12-h dark cycle, ethanol intakes averaged approximately $1 \mathrm{~g} / \mathrm{kg}$ for each access period; peak BACs at the end of an access period were approximately $75 \mathrm{mg} \%$ (Murphy et al., 1986). Overall, these results indicate that the selection process for the $\mathrm{P}$ rats also produced animals that drink sufficient ethanol to attain pharmacologically significant BACs. In fact, this early study indicated that binge levels of ethanol intake could be achieved with scheduled access to ethanol during the dark phase.

Subsequent studies indicated that the availability of higher concentrations of ethanol (10 vs. $15 \%)$ and the availability of multiple concentrations (15\% vs. 10,20 , and $30 \%)$ resulted in 
higher ethanol intakes and BACs (McBride et al., 2013; Rodd-Henricks et al., 2001). Under certain drinking conditions, BACs exceeding $150 \mathrm{mg} \%$ and reaching $200 \mathrm{mg} \%$ can be attained by P rats (McBride et al., 2013; Rodd-Henricks et al., 2001); these BACs readily produce motor impairment and sedation (Lumeng, Waller, McBride, \& Li, 1982). Ethanol intakes that produce BACs approaching $200 \mathrm{mg} \%$ have been termed 'loss-of-control' drinking (McBride et al., 2013).

Even though the $\mathrm{P}$ and HAD lines meet the selection criteria, it is important to establish these lines as suitable animal models to provide a better understanding of the neurobiological bases underlying alcohol use disorders (AUDs). The closer the animal model is to the human condition, the greater is the potential for understanding the biology of the condition. However, it is only possible for an animal to exhibit certain characteristics of the broad spectrum of features associated with the human alcoholic conditions.

\section{Criteria for an animal model of alcoholism}

The criteria of an animal model of alcoholism have been proposed (Cicero, 1979; Lester \& Freed, 1973). These criteria were proposed for application to animal studies and were not proposed to address diagnostic criteria. The proposed criteria were designed to indicate the main features that could be applied to animals that would address many of the features applied to humans, except those features that are unique to humans. The original 6 criteria are summarized in Table 1 along with studies with the $\mathrm{P}$ and HAD rats that attempted to satisfy these criteria. The animal should orally self-administer alcohol under free-choice conditions, and the amount of alcohol ingested should produce pharmacologically relevant BACs. If social drinking is being studied, then BACs well below $50 \mathrm{mg} \%$ and closer to 10 $\mathrm{mg} \%$ would be adequate. However, alcoholics are likely to consume amounts of alcohol sufficient to approach or exceed intoxicating BAC levels, which would be greater than 50 $\mathrm{mg} \%$. In the case of binge drinking, BACs would have to reach $80 \mathrm{mg} \%$, according to the National Institute on Alcohol Abuse and Alcoholism (NIAAA) standards (2004).

The general effects of alcohol in rodents are similar to the general effects in humans. Low blood concentrations (10-25 $\mathrm{mg} \%$ ) are stimulating, concentrations of $50-100 \mathrm{mg} \%$ produce motor impairing effects, concentrations of $150-200 \mathrm{mg} \%$ are sedative, and concentrations in the range of 300-400 $\mathrm{mg} \%$ can be toxic. Under 24-h free-choice conditions, the P rat will voluntarily consume 5-8 g/kg/day and produce BACs in the range of 50-200 $\mathrm{mg} \%(\mathrm{Li}$, Lumeng, McBride, \& Waller, 1979; Lumeng \& Li, 1986; Murphy et al., 1986). Under scheduled access conditions, P and HAD rats will consume $2-3 \mathrm{~g} / \mathrm{kg}$ ethanol within a 1- or 2-h session to produce BACs that reach $80-100 \mathrm{mg} \%$ on a daily basis (Bell, Rodd, Lumeng, Murphy, \& McBride, 2006; Murphy et al., 1986; Oster et al., 2006; Rodd et al., 2003).

Additional criteria are a) alcohol should produce positive reinforcing effects, and b) the animals should be consuming the alcohol for its pharmacological effects and not solely for its caloric value, taste, or smell. Also, the animals should be willing to work to obtain the alcohol. Several studies demonstrated that $\mathrm{P}$ rats will operant respond even with high workload (fixed-ratio) requirements (Ciccicioppo, Angeletti, \& Weiss, 2001; Czachowski \& Samson, 2002; Files, Samson, Denning, \& Marvin, 1998; Murphy, Gatto, McBride, 
Lumeng, \& Li, 1989; Rodd et al., 2003; Samson, Files, Denning, \& Marvin, 1998), achieving estimated BACs in excess of $80 \mathrm{mg} \%$ (Rodd et al., 2003). Moreover, recently it has been demonstrated that $\mathrm{P}$ rats will exhibit 'loss-of-control' binge-like alcohol drinking and attain BACs of $200 \mathrm{mg} \%$ on a daily basis (McBride et al., 2013).

$\mathrm{P}$ rats consume alcohol for its pharmacological effects and not solely for its caloric value, taste, or smell, as indicated by the findings that $\mathrm{P}$ and non-preferring (NP) rats react to the taste and smell of ethanol similarly (Bice \& Kiefer, 1990); the P rat will self-administer high quantities of ethanol intra-gastrically (Murphy et al., 1988; Waller, McBride, Gatto, Lumeng, \& Li, 1984), and will continue to consume high amounts of alcohol in the presence of other highly palatable solutions and caloric sources (Lankford, Roscoe, Pennington, \& Myers, 1991; Lumeng, Hawkins, \& Li, 1977; Nowak, McKinzie, McBride, \& Murphy, 1999; Russell, McBride, Lumeng, Li, \& Murphy, 1996; Toalston et al., 2008). In these latter cases, the ethanol and sweet solutions are concurrently available and the rat has free-choice between the two solutions. In the case of intra-gastric self-administration, BACs of 115-300 $\mathrm{mg} \%$ were readily reached (Waller, McBride, Gatto, Lumeng, \& Li, 1984).

Other criteria that are needed to establish an animal model of alcoholism are that both metabolic and functional tolerance should develop after a period of free-choice alcohol consumption. The P rat has been shown to develop metabolic tolerance (Lumeng \& $\mathrm{Li}$, 1986) following chronic free-choice drinking. Tolerance to the motor-impairing (Gatto et al., 1987) and aversive (Stewart, McBride, Lumeng, Li, \& Murphy, 1991) effects of alcohol following chronic free-choice drinking demonstrated the development of functional tolerance.

A final criterion (Cicero, 1979; Lester \& Freed, 1973) to satisfy is that physical signs of dependence should develop when alcohol is withdrawn after a period of chronic consumption. The P rat developed dependence following chronic free-choice drinking as indicated by physical signs of withdrawal when ethanol was removed (Kampov-Polevoy, Matthews, Gause, Morrow, \& Overstreet, 2000; Waller, McBride, Lumeng, \& Li, 1982).

Thus, the P rat satisfies all the original criteria (Table 1) proposed for a suitable animal model of alcoholism. Although not studied as extensively as the P rat, the HAD replicate lines of rats satisfy several of the criteria for an animal model of alcoholism (Table 1). The $\mathrm{P}$ and HAD rats are good animal models for studying a) genetic factors that contribute to vulnerability to high alcohol drinking behavior, b) mechanisms underlying the CNS rewarding effects of ethanol and mediating high alcohol-drinking behavior, c) long-range consequences of alcohol drinking, and d) factors contributing to the development of excessive (dangerous) levels of alcohol intake.

\section{Other important characteristics of an animal model of alcoholism}

The original criteria proposed by Lester \& Freed (1973) and Cicero (1979) for characterizing an animal model of alcoholism did not incorporate relapse drinking. Alcoholism is a chronically relapsing disorder. Repeated episodes of relapse drinking are common among alcoholics (Lim \& Keefe, 2004; Malcolm, Herron, Anton, Roberts, \& Moore, 2000a; Malcolm, Roberts, Wang, Myrick, \& Anton, 2000b; McKay, Franklin, 
Patapis, \& Lynch, 2006). Therefore, another criterion (proposed by McBride \& Li, 1998) should be that the animal model readily demonstrates relapse drinking after a prolonged period of abstinence.

\section{Relapse drinking}

Relapse drinking is defined as a return to a high level of intake that is equal to or greater than the amount of ethanol intake prior to the period of abstinence, and produces pharmacologically relevant BACs. Both the $\mathrm{P}$ and HAD rats demonstrate relapse drinking under both free-choice drinking and operant conditions; moreover, these lines have significantly higher ethanol intakes following a prolonged period of abstinence (at least 2 weeks), which progressively increases with repeated cycles of drinking and abstinence (Oster et al., 2006; Rodd et al., 2003; Rodd-Henricks et al., 2000a, b). The temporary increase in the intake of ethanol over baseline conditions when ethanol is reinstated after a prolonged abstinence period is termed the Alcohol Deprivation Effect (ADE).

The ADE phenomenon has been observed in the $\mathrm{P}$ rat under a variety of experimental designs (McKinzie et al., 1998; Rodd-Henricks et al., 2000b; Sinclair \& Li, 1989). Furthermore, with concurrent availability of 10, 20, and 30\% ethanol under 24-h free-choice drinking conditions, following either a 2- or 8-week abstinence period, P rats will increase their intakes from $\sim 6 \mathrm{~g} / \mathrm{kg} / \mathrm{day}$ to $\sim 11 \mathrm{~g} / \mathrm{kg} /$ day (Rodd-Henricks et al., 2001). More importantly, during the first $2 \mathrm{~h}$ of access, the $\mathrm{P}$ rats consume $\sim 4 \mathrm{~g} / \mathrm{kg}$ ethanol. With repeated deprivations, the 24- $\mathrm{h}$ intakes reached $\sim 16 \mathrm{~g} / \mathrm{kg} /$ day with $\sim 6 \mathrm{~g} / \mathrm{kg}$ consumed in the first $2 \mathrm{~h}$. Trunk blood BACs ranged from 160 to $205 \mathrm{mg} \%$ when measured $3 \mathrm{~h}$ into the dark cycle after the ethanol solutions were returned (Rodd-Henricks et al., 2001).

$\mathrm{P}$ rats also demonstrate an ADE under operant conditions (conducted during the dark phase) with only a single ethanol concentration (15\%) vs. water (Rodd et al., 2003). P rats showed an ADE following a 2- or 5-week abstinence period. Estimated intakes during the 1-h operant session increased from $\sim 1.3 \mathrm{~g} / \mathrm{kg}$ at baseline (before deprivation) to $\sim 3.8 \mathrm{~g} / \mathrm{kg}$ when access to ethanol was returned following a 3rd prolonged deprivation period; this relapse level of intake would produce BACs exceeding $150 \mathrm{mg} \%$.

The HAD replicate lines demonstrate an ADE under 24-h free-choice (Rodd-Henricks et al., 2000a), but only after a 2nd deprivation. Similarly, with an abbreviated relapse protocol, HAD rats from both replicate lines displayed an ADE, achieving BACs of 70-100 mg\% (Bell et al., 2008). Under operant conditions (1-h sessions with 15\% ethanol vs. water) during the dark cycle, HAD rats showed a reliable ADE after the 3rd deprivation (Oster et al., 2006). The estimated ethanol intakes (3.0-3.5 g/ $\mathrm{kg} / \mathrm{session})$ on the $1 \mathrm{st}$ reacquisition day would be sufficient to produce BACs over $150 \mathrm{mg} \%$. Overall, the P and HAD rats appear to be excellent animal models for studying relapse under binge drinking conditions.

\section{Alcohol-seeking behavior}

Craving, or a strong desire to use alcohol, is one of the DSM-V criteria for diagnosing AUDs (Table 2). Many individuals who are dependent on alcohol experience craving (De Bruijn, Korxec, Koerselman, \& van Den Brink, 2004). A recent study suggested that alcohol craving may be a predictor of relapse (Schneekloth et al., 2012). Because of the subjective 
measure of craving, it is difficult to assess and quantify in humans. The expression of an $\mathrm{ADE}$ and/or ethanol-seeking behavior may be animal measures of 'craving-like' behavior. The $\mathrm{P}$ and HAD1,2 rats express a robust ADE following prolonged abstinence (Oster et al., 2006; Rodd et al., 2003; Rodd-Henricks et al., 2000a, 2001). Similarly, P rats express robust ethanol-seeking behavior after a prolonged alcohol-free period following extinction training (Hauser et al., 2011, 2012a; Rodd et al., 2006; Rodd-Henricks et al., 2002a, b).

Drug-seeking behavior can be induced by distinct cues associated with drug selfadministration, priming with low doses of the drug, and stress (e.g., foot shocks). Most studies to date use these experimental approaches to study drug reinstatement responding, including alcohol (reviewed in Rodd, Bell, Sable, Murphy, \& McBride, 2004b). The Pavlovian Spontaneous Recovery (PSR) procedure has been employed to study alcoholseeking behavior (Rodd et al., 2006; Rodd-Henricks et al., 2002a, b). The PSR procedure tests the responses on the ethanol lever vs. the water lever in the absence of any reinforcer. In this procedure, the $\mathrm{P}$ rat first undergoes 6-8 weeks of daily operant ethanol selfadministration, followed by 7-9 extinction sessions (1-h operant sessions without any fluids present). After the extinction sessions, the $\mathrm{P}$ rats are placed in their home cages for 2-8 weeks without ethanol or any additional operant experience. Without any priming doses, discrete cues (other than the contextual cues of the operant chamber), or stress, the animals are returned to the operant chamber without ethanol or water present and allowed to respond. Under these conditions, the P rats spontaneously respond on the ethanol lever several-fold higher than on the water lever (Rodd et al., 2006; Rodd-Henricks et al., 2002a, b). This procedure parallels the human alcoholic who goes through detoxification and is alcohol-free for a prolonged period.

\section{Adolescent alcohol drinking}

Alcohol use often begins in the second decade of life, with the first use of alcohol typically occurring in early adolescence (13-14 years of age; Faden, 2006). Results from the National Longitudinal Alcohol Epidemiological Survey indicated that individuals initiating alcohol use before 14 years old had a 4-fold higher rate of lifetime alcohol dependence than individuals that initiated use after the age of 20 (Grant \& Dawson, 1997). The importance of the first episode of alcohol intoxication occurring during the mid-teens is included in the DSM-V section on addictive behaviors (Table 3). Therefore, another important feature to be considered in an animal model is that significant ethanol intakes producing pharmacologically relevant BACs are demonstrated under free-choice conditions during adolescence. The adolescent window in rats is narrow (28-42 days of age) and does not allow sufficient time for inducing non-selectively bred rats to voluntarily consume alcohol to produce significant BACs. Both the P (Bell, Rodd, Lumeng, Murphy, \& McBride, 2006; Bell et al., 2003; McBride et al., 2005) and HAD replicate (Bell et al., 2004) rats fit the criteria proposed by Cloninger (1987) for the early onset alcoholic, i.e., the selectively bred rats exhibit high alcohol drinking behavior during adolescence that is similar to adult ethanol intakes (Bell et al., 2011). These findings are important since it is possible to use these lines of rats to study mechanisms underlying the development of adolescent alcohol drinking, and, as well, to study the long-range consequences of adolescent alcohol drinking. 


\section{The utility of P and HAD rats for studying co-abuse of alcohol with other drugs}

Good animal models of high alcohol drinking behavior offer excellent experimental approaches toward studying mechanisms underlying the co-abuse of alcohol with other drugs. Whereas common stock strains of rats will self-administer most drugs of abuse, e.g., cocaine, these stock rats will not usually drink sufficient alcohol to attain abuse levels, i.e., intoxication.

Alcohol and nicotine are the two most frequently used drugs in the world and are often used together (Kandel, Chen, Warner, Kessler, \& Grant, 1997). In individuals diagnosed with alcohol dependency, the rate of smoking is estimated to be between 80 and $97 \%$ (Gulliver et al., 1995; Hughes, 1995, 1996; Hurt et al., 1994; John, Hill, Rumpf, Hapke, \& Meyer, 2003a; John et al., 2003b). Epidemiological studies of U.S. populations indicate that, for individuals with cannabis use disorders, there is a $45-80 \%$ lifetime prevalence of developing a co-morbid alcohol use disorder (Agosti, Nunes, \& Levin, 2002; Regier et al., 1990; Stinson, Ruan, Pickering, \& Grant, 2006). Cocaine is another drug that is often co-abused with alcohol. A majority of individuals dependent on cocaine can also be diagnosed as alcohol dependent (Carroll, Rounsaville, \& Bryant, 1993; Miller, Millman, \& Keskinen, 1989). Alcoholics are more likely to use cocaine, and cocaine use can increase alcohol consumption (Heil, Badger, \& Higgins, 2001; Staines, Magura, Foote, Deluca, \& Kosanke, 2001). Therefore, there is an important need to understand the brain mechanisms contributing to the co-abuse of alcohol with other drugs of abuse.

Despite the high importance of studying the co-abuse of alcohol with other drugs of abuse, there have been relatively few animal models developed to address this issue. Lê et al. (2010) used male Wistar rats and developed an operant procedure for intravenous (i.v.) nicotine and oral ethanol self-administration in the same session. Hauser et al. (2012b) developed an oral operant co-abuse model for concurrent ethanol and nicotine selfadministration by $\mathrm{P}$ rats. With the latter procedure, $\mathrm{P}$ rats reached BACs that were at binge drinking levels (100 $\mathrm{mg} \%)$ and also produced blood nicotine levels $(25 \mathrm{ng} / \mathrm{mL})$ that were comparable to human nicotine levels attained following smoking.

Another reason for using the selectively bred P rat to study the use and co-use of drugs of abuse is that selective breeding for high alcohol consumption also appears to be associated with increased sensitivity to the reinforcing effects of various drugs of abuse. Compared to alcohol-non-preferring (NP) rats, the P rat appears to be more sensitive to the i.v. selfadministration of nicotine (Lê et al., 2006). In support of this conclusion, a more recent study (Hauser et al., 2013) indicated that the P rats were more sensitive than Wistar rats to the reinforcing effects of nicotine in the posterior VTA. Another study (Katner et al., 2011) indicated that $P$ rats were more sensitive than Wistar rats to the reinforcing effects of cocaine in the nucleus accumbens shell. These results with nicotine and cocaine are consistent with previous studies indicating that the pVTA (Gatto, McBride, Murphy, Lumeng, \& Li, 1994; Rodd et al., 2004a) and nucleus accumbens shell (Engleman et al., 2009) of P rats are more sensitive than Wistar or NP rats to the reinforcing effects of ethanol. Moreover, chronic alcohol drinking by $\mathrm{P}$ rats increases the sensitivity of the posterior VTA to the reinforcing effects of ethanol (Rodd et al., 2005a, b). Overall, these studies support the idea that there is an association between selective breeding for high 
alcohol drinking behavior and sensitivity to the reinforcing effects of nicotine and cocaine, as well as ethanol, and that chronic drinking can increase the CNS rewarding effects of ethanol. Thus far, sensitivity to the rewarding effects of other drugs of abuse has not been tested in the P rat.

\section{Conclusions}

The characteristics of $\mathrm{P}$ and HAD rats make these animals very useful for studying the many complex mechanisms involved with regulating high alcohol drinking behavior and the development of alcohol addiction and AUDs. Table 1 lists the original critical criteria proposed to establish a suitable animal model to study alcoholism. These criteria focused on making a strong animal model and did not include criteria that were unique to humans (Table 2). The P rat satisfies all of the original criteria and the HAD1,2 rat satisfies 4 of the 6 original criteria. The development of tolerance and physical signs of withdrawal following chronic drinking were not examined in the HAD1,2 rats. Most of the diagnostic criteria stated in DSM-IV for evaluating AUDs are also stated in DSM-V. Table 2 compares the characteristics of $\mathrm{P}$ and HAD1,2 rats with some of the diagnostic criteria given in DSM-IV and DSM-V. The P rat (and to some degree the HAD1,2 rat) expresses characteristics that could satisfy diagnostic criteria for defining an individual with an AUD. Table 3 summarizes some additional important features of AUDs that also can be studied with the $\mathrm{P}$ and HAD1,2 rats. The $\mathrm{P}$ and HAD rats are excellent animal models for studying brain mechanisms involved in the voluntary intake of alcohol under 24-h free-choice, oral scheduled access or operant limited-access conditions. Under the latter 2 conditions (conducted during the dark phase), these rats will consume sufficient ethanol to reach and exceed binge levels $(80 \mathrm{mg} \%$ ). The $\mathrm{P}$ rat spontaneously exhibits robust alcohol-seeking behavior without priming, discrete cues, or stress, after a period of prolonged abstinence. In addition, these rats can exhibit loss-of-control drinking (BACs of $200 \mathrm{mg} \%$ ). Both P and HAD rats demonstrate a robust ADE under relapse conditions, and both exhibit early-onset alcoholic characteristics, in that, during adolescence, these lines have alcohol intakes that are comparable to adult levels. Finally, the P and HAD rats offer the potential of being useful animal models for studying the co-abuse of alcohol with other drugs.

\section{Acknowledgments}

Research findings presented in this review were supported by NIAAA research grants AA07611, AA010721, AA012262, AA011261, AA010256, and AA019366.

\section{References}

Agosti V, Nunes E, Levin F. Rates of psychiatric comorbidity among U.S. residents with lifetime cannabis dependence. The American Journal of Drug and Alcohol Abuse. 2002; 28:643-652. [PubMed: 12492261]

Bell RL, Kimpel MW, McClintick JN, Strother WN, Carr LG, Liang T, et al. Gene expression changes in the nucleus accumbens of alcohol-preferring rats following chronic ethanol consumption. Pharmacology, Biochemistry, and Behavior. 2009; 94:131-147.

Bell RL, Rodd ZA, Hsu CC, Lumeng L, Li TK, Murphy JM, et al. Effects of concurrent access to a single concentration or multiple concentrations of ethanol on ethanol intake by periadolescent highalcohol-drinking rats. Alcohol. 2004; 33:107-115. [PubMed: 15528008] 
Bell RL, Rodd ZA, Lumeng L, Murphy JM, McBride WJ. The alcohol-preferring P rat and animal models of excessive alcohol drinking. Addiction Biology. 2006; 11:270-288. [PubMed: 16961759]

Bell RL, Rodd ZA, Schultz JA, Peper CL, Lumeng L, Murphy JM, et al. Effects of short deprivation and re-exposure intervals on the ethanol drinking behavior of selectively bred high alcoholconsuming rats. Alcohol. 2008; 42:407-416. [PubMed: 18486429]

Bell RL, Rodd ZA, Smith RJ, Toalston JE, Franklin KM, McBride WJ. Modeling binge-like ethanol drinking by peri-adolescent and adult P rats. Pharmacology, Biochemistry, and Behavior. 2011; 100:90-97.

Bell RL, Rodd-Henricks ZA, Kuc KA, Lumeng L, Li TK, Murphy JM, et al. Effects of concurrent access to a single concentration or multiple concentrations of ethanol on the intake of ethanol by male and female periadolescent alcohol-preferring (P) rats. Alcohol. 2003; 29:137-148. [PubMed: 12798969]

Bice PJ, Kiefer SW. Taste reactivity in alcohol preferring and nonpreferring rats. Alcoholism: Clinical and Experimental Research. 1990; 14:721-727.

Carroll KM, Rounsaville BJ, Bryant KJ. Alcoholism in treatment-seeking cocaine abusers: clinical and prognostic significance. Journal of Studies on Alcoholism. 1993; 54:199-208.

Ciccocioppo R, Angeletti S, Weiss F. Long-lasting resistance to extinction of response reinstatement induced by ethanol-related stimuli: role of genetic preference. Alcoholism: Clinical and Experimental Research. 2001; 25:1414-1419.

Cicero, TJ. A critique of animal analogues of alcoholism. In: Majchrowicz, E.; Noble, EP., editors. Biochemistry and Pharmacology of Ethanol. Vol. 2. New York: Plenum Press; 1979. p. 533-560.

Cloninger CR. Neurogenetic adaptive mechanisms in alcoholism. Science. 1987; 236:410-416. [PubMed: 2882604]

Czachowski CL, Samson HH. Ethanol- and sucrose-reinforced appetitive and consummatory responding in HAD1, HAD2, and P rats. Alcoholism: Clinical and Experimental Research. 2002; 26:1653-1661.

de Bruijn C, Korzec A, Koerselman F, van Den Brink W. Craving and withdrawal as core symptoms of alcohol dependence. The Journal of Nervous and Mental Disease. 2004; 192:494-502. [PubMed: 15232320]

Engleman EA, Ding ZM, Oster SM, Toalston JE, Bell RL, Murphy JM, et al. Ethanol is selfadministered into the nucleus accumbens shell, but not the core: evidence of genetic sensitivity. Alcoholism: Clinical and Experimental Research. 2009; 33:2162-2171.

Eriksson K. The estimation of heritability for the self-selection of alcohol in the albino rat. Annales Medicinae Experimentalis et Biologiae Fenniae. 1969; 47:172-174. [PubMed: 5360660]

Fadda F, Mosca E, Colombo G, Gessa GL. Effect of spontaneous ingestion of ethanol on brain dopamine metabolism. Life Sciences. 1989; 44:281-287. [PubMed: 2915601]

Faden VB. Trends in initiation of alcohol use in the United States 1975 to 2003. Alcoholism: Clinical and Experimental Research. 2006; 30:1011-1022.

Files FJ, Samson HH, Denning CE, Marvin S. Comparison of alcohol-preferring and nonpreferring selectively bred rat lines. II. Operant self-administration in a continuous-access situation. Alcoholism: Clinical and Experimental Research. 1998; 22:2147-2158.

Gatto GJ, McBride WJ, Murphy JM, Lumeng L, Li TK. Ethanol self-infusion into the ventral tegmental area by alcohol-preferring rats. Alcohol. 1994; 11:557-564. [PubMed: 7865158]

Gatto GJ, Murphy JM, Waller MB, McBride WJ, Lumeng L, Li TK. Chronic ethanol tolerance through free-choice drinking in the $\mathrm{P}$ line of alcohol-preferring rats. Pharmacology, Biochemistry, and Behavior. 1987; 28:111-115.

Grant BF, Dawson DA. Age of onset of alcohol use and its association with DSM-IV alcohol abuse and dependence: results from the National Longitudinal Alcohol Epidemiologic Survey. Journal of Substance Abuse. 1997; 9:103-110. [PubMed: 9494942]

Gulliver SB, Rohsenow DJ, Colby SM, Dey AN, Abrams DB, Niaura RS, et al. Interrelationship of smoking and alcohol dependence, use and urges to use. Journal of Studies on Alcohol. 1995; 56:202-206. [PubMed: 7760567] 
Hauser SR, Bracken AL, Deehan GA Jr, Toalston JE, Ding ZM, Truitt WA, et al. Selective breeding for high alcohol preference increases the sensitivity of the posterior VTA to the reinforcing effects of nicotine. Addiction Biology. 2013 [E-pub ahead of print].

Hauser SR, Ding ZM, Getachew B, Toalston JE, Oster SM, McBride WJ, et al. The posterior ventral tegmental area mediates alcohol-seeking behavior in alcohol-preferring rats. The Journal of Pharmacology and Experimental Therapeutics. 2011; 336:857-865. [PubMed: 21148248]

Hauser SR, Getachew B, Oster SM, Dhaher R, Ding ZM, Bell RL, et al. Nicotine modulates alcoholseeking and relapse by alcohol-preferring $(\mathrm{P})$ rats in a time-dependent manner. Alcoholism: Clinical and Experimental Research. 2012a; 36:43-54.

Hauser SR, Katner SN, Deehan GA Jr, Ding ZM, Toalston JE, Scott BJ, et al. Development of an oral operant nicotine/ethanol co-use model in alcohol-preferring (p) rats. Alcoholism: Clinical and Experimental Research. 2012b; 36:1963-1972.

Heil SH, Badger GJ, Higgins ST. Alcohol dependence among cocaine-dependent outpatients: demographics, drug use, treatment outcome and other characteristics. Journal of Studies on Alcohol. 2001; 62:14-22. [PubMed: 11271960]

Hughes, JR. Clinical implications of the association between smoking and alcoholism. In: Fertig, J.; Fuller, R., editors. Alcohol and Tobacco: From Basic Science to Policy. Washington, D.C: NIAAA Research Monograph; 1995. p. 171-185.

Hughes JR. Treating smokers with current or past alcohol dependence. American Journal of Health Behavior. 1996; 20:286-290.

Hurt RD, Eberman KM, Croghan IT, Offord KP, Davis LJ Jr, Morse RM, et al. Nicotine dependence treatment during inpatient treatment for other addictions: a prospective intervention trial. Alcoholism: Clinical and Experimental Research. 1994; 18:867-872.

John U, Hill A, Rumpf HJ, Hapke U, Meyer C. Alcohol high risk drinking, abuse and dependence among tobacco smoking medical care patients and the general population. Drug and Alcohol Dependence. 2003a; 69:189-195. [PubMed: 12609700]

John U, Meyer C, Rumpf HJ, Schumann A, Thyrian JR, Hapke U. Strength of the relationship between tobacco smoking, nicotine dependence and the severity of alcohol dependence syndrome criteria in a population-based sample. Alcohol and Alcoholism. 2003b; 38:606-612. [PubMed: 14633650]

Kampov-Polevoy AB, Matthews DB, Gause L, Morrow AL, Overstreet DH. P rats develop physical dependence on alcohol via voluntary drinking: changes in seizure thresholds, anxiety, and patterns of alcohol drinking. Alcoholism: Clinical and Experimental Research. 2000; 24:278-284.

Kandel D, Chen K, Warner LA, Kessler RC, Grant B. Prevalence and demographic correlates of symptoms of last year dependence on alcohol, nicotine, marijuana and cocaine in the U.S. population. Drug and Alcohol Dependence. 1997; 44:11-29. [PubMed: 9031816]

Katner SN, Oster SM, Ding ZM, Deehan GA Jr, Toalston JE, Hauser SR, et al. Alcohol-preferring (P) rats are more sensitive than Wistar rats to the reinforcing effects of cocaine self-administered directly into the nucleus accumbens shell. Pharmacology, Biochemistry, and Behavior. 2011; 99:688-695.

Lankford MF, Roscoe AK, Pennington SN, Myers RD. Drinking of high concentrations of ethanol versus palatable fluids in alcohol-preferring $(\mathrm{P})$ rats: valid animal model of alcoholism. Alcohol. 1991; 8:293-299. [PubMed: 1908249]

Lê AD, Li Z, Funk D, Shram M, Li TK, Shaham Y. Increased vulnerability to nicotine selfadministration and relapse in alcohol-naïve offspring of rats selectively bred for high alcohol intake. The Journal of Neuroscience. 2006; 26:1872-1879. [PubMed: 16467536]

Lê AD, Lo S, Harding S, Juzytsch W, Marinelli PW, Funk D. Coadministration of intravenous nicotine and oral alcohol in rats. Psychopharmacology. 2010; 208:475-486. [PubMed: 20013113]

Lester D, Freed EX. Criteria for an animal model of alcoholism. Pharmacology, Biochemistry, and Behavior. 1973; 1:103-107.

Li TK, Lumeng L, Doolittle DP. Selective breeding for alcohol preference and associated responses. Behavior Genetics. 1993; 23:163-170. [PubMed: 8099788]

Li TK, Lumeng L, Doolittle DP, Carr LG. Molecular associations of alcohol-seeking behavior in rat lines selectively bred for high and low voluntary ethanol drinking. Alcohol and Alcoholism, Supplement. 1991; 1:121-124. [PubMed: 1845526] 
Li TK, Lumeng L, McBride WJ, Waller MB. Progress toward a voluntary oral consumption model of alcoholism. Drug and Alcohol Dependence. 1979; 4:45-60. [PubMed: 41697]

Li, TK.; Lumeng, L.; McBride, WJ.; Waller, MB. Indiana selection studies on alcohol-related behaviors. In: McClearn, GE.; Deitrich, RA.; Ervin, VG., editors. Development of Animal Models as Pharmacogenetic Tools. Rockville, MD: NIAAA Research Monograph No. 6; 1981. p. 171-191.

Lim JK, Keeffe EB. Liver transplantation for alcoholic liver disease: current concepts and length of sobriety. Liver Transplantation. 2004; 10:S31-S38. [PubMed: 15382288]

Lumeng, L.; Hawkins, DT.; Li, TK. New strains of rats with alcohol preference and nonpreference. In: Thurman, RG.; Williamson, JR.; Drott, H.; Chance, B., editors. Alcohol and Aldehyde Metabolizing Systems. Vol. 3. New York: Academic Press; 1977. p. 537-544.

Lumeng L, Li TK. The development of metabolic tolerance in the alcohol-preferring P rats: comparison of forced and free-choice drinking of ethanol. Pharmacology, Biochemistry, and Behavior. 1986; 25:1013-1020.

Lumeng L, Waller MB, McBride WJ, Li TK. Different sensitivities to ethanol in alcohol-preferring and -nonpreferring rats. Pharmacology, Biochemistry, and Behavior. 1982; 16:125-130.

Malcolm R, Herron JE, Anton RF, Roberts J, Moore J. Recurrent detoxification may elevate alcohol craving as measured by the Obsessive Compulsive Drinking scale. Alcohol. 2000a; 20:181-185. [PubMed: 10719797]

Malcolm R, Roberts JS, Wang W, Myrick H, Anton RF. Multiple previous detoxifications are associated with less responsive treatment and heavier drinking during an index outpatient detoxification. Alcohol. 2000b; 22:159-164. [PubMed: 11163123]

Mardones J, Segovia-Riquelme N. Thirty-two years of selection of rats by ethanol preference: UChA and UChB strains. Neurobehavioral Toxicology and Teratology. 1983; 5:171-178. [PubMed: 6683362]

McBride WJ, Bell RL, Rodd ZA, Strother WN, Murphy JM. Adolescent alcohol drinking and its longrange consequences. Studies with animal models. Recent Developments in Alcoholism. 2005; 17:123-142. [PubMed: 15789863]

McBride WJ, Kimpel MW, McClintick JN, Ding ZM, Hauser SR, Edenberg HJ, et al. Changes in gene expression within the ventral tegmental area following repeated excessive binge-like alcohol drinking by alcohol-preferring (P) rats. Alcohol. 2013; 47:367-380. [PubMed: 23714385]

McBride WJ, Li TK. Animal models of alcoholism: neurobiology of high alcohol-drinking behavior in rodents. Critical Reviews in Neurobiology. 1998; 12:339-369. [PubMed: 10348615]

McClearn GE, Rodgers DA. Differences in alcohol preference among strains of mice. QJ Stud Alcohol. 1959; 20:691-695.

McKay JR, Franklin TR, Patapis N, Lynch KG. Conceptual, methodological, and analytical issues in the study of relapse. Clinical Psychology Review. 2006; 26:109-127. [PubMed: 16371242]

McKinzie DL, Nowak KL, Yorger L, McBride WJ, Murphy JM, Lumeng L, et al. The alcohol deprivation effect in the alcohol-preferring $\mathrm{P}$ rat under free-drinking and operant access conditions. Alcoholism: Clinical and Experimental Research. 1998; 22:1170-1176.

Miller NS, Millman RB, Keskinen S. The diagnosis of alcohol, cocaine, and other drug dependence in an inpatient treatment population. Journal of Substance Abuse Treatment. 1989; 6:37-40. [PubMed: 2709471]

Murphy JM, Gatto GJ, McBride WJ, Lumeng L, Li TK. Operant responding for oral ethanol in the alcohol-preferring P and alcohol-nonpreferring NP lines of rats. Alcohol. 1989; 6:127-131. [PubMed: 2713085]

Murphy JM, Gatto GJ, Waller MB, McBride WJ, Lumeng L, Li TK. Effects of scheduled access on ethanol intake by the alcohol-preferring (P) line of rats. Alcohol. 1986; 3:331-336. [PubMed: 3778650]

Murphy JM, Stewart RB, Bell RL, Badia-Elder NE, Carr LG, McBride WJ, et al. Phenotypic and genotypic characterization of the Indiana University rat lines selectively bred for high and low alcohol preference. Behavior Genetics. 2002; 32:363-388. [PubMed: 12405517]

Murphy JM, Waller MB, Gatto GJ, McBride WJ, Lumeng L, Li TK. Effects of fluoxetine on the intragastric self-administration of ethanol in the alcohol preferring P line of rats. Alcohol. 1988; 5:283-286. [PubMed: 3265874] 
NIAAA National Advisory Council. NIAAA Council approves definition of binge drinking. NIAAA Newsletter. 2004; 3:3.

Nowak KL, McKinzie DL, McBride WJ, Murphy JM. Patterns of ethanol and saccharin intake in P rats under limited-access conditions. Alcohol. 1999; 19:85-96. [PubMed: 10487392]

Oster SM, Toalston JE, Kuc KA, Pommer TJ, Murphy JM, Lumeng L, et al. Effects of multiple alcohol deprivations on operant ethanol self-administration by high-alcohol-drinking replicate rat lines. Alcohol. 2006; 38:155-164. [PubMed: 16905441]

Regier DA, Farmer ME, Rae DS, Locke BZ, Keith SJ, Judd LL, et al. Co-morbidity of mental disorders with alcohol and other drugs of abuse. Results from the Epidemiologic Catchment Area (ECA) Study. Journal of the American Medical Association. 1990; 264:2511-2518. [PubMed: 2232018]

Richter CP, Campbell KH. Alcohol taste thresholds and concentrations of solution preferred by rats. Science. 1940; 91:507-508. [PubMed: 17847448]

Rodd ZA, Bell RL, Kuc KA, Murphy JM, Lumeng L, Li TK, et al. Effects of repeated alcohol deprivations on operant ethanol self-administration by alcohol-preferring $(\mathrm{P})$ rats. Neuropsychopharmacology. 2003; 28:1614-1621. [PubMed: 12799615]

Rodd ZA, Bell RL, McQueen VK, Davids MR, Hsu CC, Murphy JM, et al. Chronic ethanol drinking by alcohol-preferring rats increases the sensitivity of the posterior ventral tegmental area to the reinforcing effects of ethanol. Alcoholism: Clinical and Experimental Research. 2005a; 29:358366.

Rodd ZA, Bell RL, McQueen VK, Davids MR, Hsu CC, Murphy JM, et al. Prolonged increase in the sensitivity of the posterior ventral tegmental area to the reinforcing effects of ethanol following repeated exposure to cycles of ethanol access and deprivation. The Journal of Pharmacology and Experimental Therapeutics. 2005b; 315:648-657. [PubMed: 16076936]

Rodd ZA, Bell RL, Melendez RI, Kuc KA, Lumeng L, Li TK, et al. Comparison of intracranial selfadministration of ethanol within the posterior ventral tegmental area between alcohol-preferring and Wistar rats. Alcoholism: Clinical and Experimental Research. 2004a; 28:1212-1219.

Rodd ZA, Bell RL, Sable HJ, Murphy JM, McBride WJ. Recent advances in animal models of alcohol craving and relapse. Pharmacology, Biochemistry, and Behavior. 2004b; 79:439-450.

Rodd ZA, McKinzie DL, Bell RL, McQueen VK, Murphy JM, Schoepp DD, et al. The metabotropic glutamate 2/3 receptor agonist LY404039 reduces alcohol-seeking but not alcohol selfadministration in alcohol-preferring (P) rats. Behavioural Brain Research. 2006; 171:207-215. [PubMed: 16678921]

Rodd-Henricks ZA, Bell RL, Kuc KA, Murphy JM, McBride WJ, Lumeng L, et al. Effects of concurrent access to multiple ethanol concentrations and repeated deprivations on alcohol intake of alcohol-preferring rats. Alcoholism: Clinical and Experimental Research. 2001; 25:1140-1150.

Rodd-Henricks ZA, Bell RL, Kuc KA, Murphy JM, McBride WJ, Lumeng L, et al. Effects of ethanol exposure on subsequent acquisition and extinction of ethanol self-administration and expression of alcohol-seeking behavior in adult alcohol-preferring $(\mathrm{P})$ rats. I. Periadolescent exposure. Alcoholism: Clinical and Experimental Research. 2002a; 26:1632-1641.

Rodd-Henricks ZA, Bell RL, Kuc KA, Murphy JM, McBride WJ, Lumeng L, et al. Effects of ethanol exposure on subsequent acquisition and extinction of ethanol self-administration and expression of alcohol-seeking behavior in adult alcohol-preferring (P) rats. II. Adult exposure. Alcoholism: Clinical and Experimental Research. 2002b; 26:1642-1652.

Rodd-Henricks ZA, McKinzie DL, Murphy JM, McBride WJ, Lumeng L, Li TK. The expression of an alcohol deprivation effect in the high-alcohol-drinking replicate rat lines is dependent on repeated deprivations. Alcoholism: Clinical and Experimental Research. 2000a; 24:747-753.

Rodd-Henricks ZA, McKinzie DL, Shaikh SR, Murphy JM, McBride WJ, Lumeng L, et al. Alcohol deprivation effect is prolonged in the alcohol preferring $(\mathrm{P})$ rat after repeated deprivations. Alcoholism: Clinical and Experimental Research. 2000b; 24:8-16.

Russell RN, McBride WJ, Lumeng L, Li TK, Murphy JM. Apomorphine and 7-OH DPAT reduce ethanol intake of P and HAD rats. Alcohol. 1996; 13:515-519. [PubMed: 8888949] 
Samson HH, Files FJ, Denning C, Marvin S. Comparison of alcohol-preferring and nonpreferring selectively bred rat lines. I. Ethanol initiation and limited access operant self-administration. Alcoholism: Clinical and Experimental Research. 1998; 22:2133-2146.

Schneekloth TD, Biernacka JM, Hall-Flavin DK, Karpyak VM, Frye MA, Loukianova LL, et al. Alcohol craving as a predictor of relapse. The American Journal on Addictions. 2012; 21(suppl 1):S20-26. [PubMed: 23786506]

Sinclair JD, Li TK. Long and short alcohol deprivation: effects on AA and P alcohol-preferring rats. Alcohol. 1989; 6:505-509. [PubMed: 2597353]

Staines GL, Magura S, Foote J, Deluca A, Kosanke N. Polysubstance use among alcoholics. Journal of Addictive Diseases. 2001; 20:53-69. [PubMed: 11760926]

Stewart RB, McBride WJ, Lumeng L, Li TK, Murphy JM. Chronic alcohol consumption in alcoholpreferring $\mathrm{P}$ rats attenuates subsequent conditioned taste aversion produced by ethanol injections. Psychopharmacology. 1991; 105:530-534. [PubMed: 1771221]

Stinson FS, Ruan WJ, Pickering R, Grant BF. Cannabis use disorders in the USA: prevalence, correlates and co-morbidity. Psychological Medicine. 2006; 36:1447-1460. [PubMed: 16854249]

Toalston JE, Oster SM, Kuc KA, Pommer TJ, Murphy JM, Lumeng L, et al. Effects of alcohol and saccharin deprivations on concurrent ethanol and saccharin operant self-administration by alcoholpreferring (P) rats. Alcohol. 2008; 42:277-284. [PubMed: 18400451]

Waller MB, McBride WJ, Gatto GJ, Lumeng L, Li TK. Intragastric self-administration of ethanol by ethanol-preferring and -nonpreferring lines of rats. Science. 1984; 225:78-80. [PubMed: 6539502]

Waller MB, McBride WJ, Lumeng L, Li TK. Induction of dependence on ethanol by free-choice drinking in alcohol-preferring rats. Pharmacology, Biochemistry, and Behavior. 1982; 16:501507. 


\section{Table 1}

Criteria proposed for a suitable animal model of alcoholism (Cicero, 1979; Lester \& Freed, 1973) and characteristics demonstrated by $\mathrm{P}$ and HAD1,2 rats

\begin{tabular}{|c|c|}
\hline Animal model criteria & Characteristics of the $P$ and HAD1,2 rats \\
\hline $\begin{array}{l}\text { The animal should orally self-administer } \\
\text { ethanol under free-choice conditions. }\end{array}$ & $\begin{array}{l}\mathrm{P} \text { and HAD1,2 rats voluntarily consume alcohol orally under free-choice conditions. Ethanol } \\
\text { intakes of 5-8 g/kg/day are readily attained (reviewed in McBride \& Li, 1998; Murphy et al., } \\
\text { 2002). }\end{array}$ \\
\hline $\begin{array}{l}\text { Ethanol self-administration should lead to } \\
\text { pharmacologically relevant BACs. }\end{array}$ & $\begin{array}{l}\text { Highly relevant BACs of } 50-200 \mathrm{mg} \% \text { ethanol can be reached with voluntary ethanol } \\
\text { drinking under 24-h or scheduled access conditions by P and HAD1,2 rats (reviewed in } \\
\text { McBride \& Li, 1998; Murphy et al., 2002). }\end{array}$ \\
\hline $\begin{array}{l}\text { Ethanol should be consumed primarily for its } \\
\text { post-ingestive pharmacological effects and not } \\
\text { solely for its caloric value, taste, or smell. }\end{array}$ & $\begin{array}{l}\text { It has been shown that taste and smell reactivity is similar for P and NP rats (Bice \& Kiefer, } \\
\text { 1990). P rats will self-administer ethanol directly into the stomach to produce intoxicating } \\
\text { BACs (Waller et al., 1984), and P and HAD1 rats will maintain high ethanol intakes even in } \\
\text { the presence of highly palatable solutions (Lankford et al., 1991; Russell et al., 1996; } \\
\text { Toalston et al., 2008). }\end{array}$ \\
\hline $\begin{array}{l}\text { Ethanol should be positively reinforcing, and } \\
\text { the animals should work to obtain ethanol. }\end{array}$ & $\begin{array}{l}\mathrm{P} \text { and HAD1,2 rats will operant respond for ethanol in sufficient amounts to produce BACs } \\
\text { that exceed } 80 \mathrm{mg} \% \text { (equivalent to human binge drinking) when food and water are available. } \\
\mathrm{P} \text { rats have a very high breakpoint for ethanol (Czachowski \& Samson, 2002; Oster et al., } \\
\text { 2006; Rodd et al., 2003). }\end{array}$ \\
\hline $\begin{array}{l}\text { Chronic ethanol consumption should lead to } \\
\text { metabolic and functional tolerance. }\end{array}$ & $\begin{array}{l}\text { P rats develop metabolic tolerance (Lumeng \& Li, 1986), and functional tolerance to the } \\
\text { motor impairing and aversive effects of ethanol (Gatto et al., 1987; Stewart et al., 1991) } \\
\text { following chronic free-choice drinking. }\end{array}$ \\
\hline $\begin{array}{l}\text { Physical signs of withdrawal should develop } \\
\text { following ethanol withdrawal after a period of } \\
\text { chronic consumption. }\end{array}$ & $\begin{array}{l}\text { P rats develop physical signs of dependence following withdrawal of ethanol after a } \\
\text { prolonged period of chronic free-choice alcohol drinking (Kampov-Polevoy et al., 2000; } \\
\text { Waller et al., 1982). }\end{array}$ \\
\hline
\end{tabular}




\section{TABLE 2}

DSM-IV \& DSM-V criteria for alcohol use disorders and characteristics of these criteria exhibited by P and HAD1, 2 rats

\section{DSM-IV}

Need for markedly increased amounts of alcohol to achieve intoxication or desired effect

Alcohol is taken to relieve or avoid withdrawal symptoms.

Unsuccessful efforts to control alcohol use

Important social, occupational, or recreational activities affected because of alcohol abuse.

A great deal of time is spent in activities necessary to obtain alcohol or recover from its effects.

Continued alcohol use despite knowledge of having a

persistent problem that is likely

to be a result of or exacerbated

by alcohol drinking

\section{Animal model}

Chronic drinking by $\mathrm{P}$ rats produces tolerance to aversive effects and increases alcohol intake (Gatto et al., 1987; Stewart et al., 1991).

Not tested in $\mathrm{P}$ or HAD rats, although $\mathrm{P}$ rats will readily drink to intoxication (BACs $>80-100 \mathrm{mg} \%$ ) on a daily basis (McBride et al., 2013).

$\mathrm{P}$ and HAD1,2 rats readily demonstrate an alcohol deprivation effect after a prolonged alcohol-free period and can attain BACs that approach $200 \mathrm{mg} \%$ (Oster et al., 2006; Rodd et al., 2003; Rodd-Henricks et al., 2000a, 2001).

Unique to human condition

$\mathrm{P}$ rats will achieve binge levels of drinking (and higher) under conditions in which access to ethanol is scheduled for 3-4 1-h sessions each day (Bell et al., 2009, 2011; McBride et al., 2013).

Unique to human condition

$P$ rats demonstrate robust alcohol-seeking behavior in the environment previously associated with ethanol selfadministration after a prolonged 'rest' period which followed extinction training (Hauser et al., 2011, 2012a; Rodd et al., 2006; Rodd-Henricks et al., 2002a, b).

$P$ rats develop physical signs of dependence in 8-24 h following withdrawal of ethanol after a prolonged period of chronic freechoice alcohol drinking (Kampov-Polevoy et al., 2000; Waller et al., 1982).

\section{DSM-V}

Need for markedly increased amounts of alcohol to achieve intoxication or desired effect

Alcohol is taken to relieve or avoid withdrawal symptoms.

Unsuccessful efforts to control alcohol use

Important social, occupational, or recreational activities are given up or reduced because of alcohol use.

A great deal of time is spent in activities necessary to obtain alcohol, use alcohol, or recover from its effects.

Continued alcohol use despite knowledge of having persistent or recurrent social or interpersonal problems caused or exacerbated by the effects of alcohol

Craving, or a strong desire to use alcohol

Physical signs of withdrawal that occur within several hours or a few days 
Table 3

\section{Additional features in DSM-V and characteristics of $\mathrm{P}$ and HAD1,2 rats}

\section{DSM-V Additional features}

Use of heavy doses of alcohol with resulting repeated and significant distress or impaired function

First episode of alcohol intoxication is likely to occur during mid-teens.

Not mentioned in DSM-V is the high prevalence of smoking in alcohol-dependent individuals (John et al. 2003a, b).

\section{Characteristics of $P$ and HAD1,2 rats}

$\mathrm{P}$ rats will consume high amounts of alcohol to produce BACs $>150 \mathrm{mg} \%$ and exhibit motor impairment and sedation (McBride et al., 2013; Rodd-Henricks et al., 2000a, 2001).

$\mathrm{P}$ and HAD1,2 rats demonstrate levels of alcohol drinking during adolescence that are comparable to adult intakes (Bell et al., 2003, 2004, 2006).

$P$ rats may be good animal models for co-abuse because a) they are more sensitive than low alcohol-consuming rats to reinforcing effects of nicotine and cocaine, and $b$ ) under binge-like conditions these rats will concurrently consume ethanol and nicotine to attain high BACs of $80 \mathrm{mg} \%$ and significant nicotine blood levels of $25 \mathrm{ng} / \mathrm{mL}$ (Hauser et al., 2012b, 2013; Katner et al., 2011). 